\title{
Spheroidisation of iron powder in a microwave plasma reactor
}

\author{
by J.H. van Laar*† I.J. van der Walt*, H. Bissett*, \\ J.C. Barry* and P.L. Crouse ${ }^{\dagger}$
}

\section{Synopsis}

Plasma-assisted spheroidisation of metal powders offers several technical advantages with respect to both the ease of materials handling and powder-metallurgical item manufacturing. Advantages include improved flowability, increased powder packing density, elimination of internal component cavities and fractures, changes in morphology resulting in decreased friction between particles and contamination during pneumatic transport and enhanced particle purity. In this empirical study, spherical iron particles were produced using a microwave plasma operating at atmospheric pressure and characterized using optical microscopy and SEM techniques. Iron powders were fed into the system at fixed operating conditions, resulting in particles with spherical structures. The theoretical estimate of the time required for melting to occur is $1.6 \mathrm{~ms}$, an order of magnitude smaller than the actual residence time.

Keywords

iron powder, spheroidisation, microwave plasma.

\section{Introduction}

Particle design and functionalization has become an increasingly popular aspect of materials synthesis and powder-metallurgical item manufacturing. One such technique involves the spheroidisation and densification of feed materials, typically in the form of chemical powders with wide particle size distributions. The major benefits of powder spheroidisation include improved powder flowability, increased powder packing density and powder purity, reductions in internal voids and defects, as well as the ability to manipulate the particles surface morphologies (Boulos, 2004). Thermal plasma processing has the potential for scale-up and for producing industrial quantities of spheroidised powder.

Thermal plasma technologies offer a wide spectrum of material synthesis and treatment options, amongst others the synthesis and spheroidisation of nano-sized ceramic and metal particles (Kumar and Selvarajan, 2006). The spheroidisation process occurs within the plasma discharge via in-flight heating and melting of the powder feed material, given high enough plasma temperatures (Fridman, 2008, p. 495). Surface tension in the molten droplets results in spherical, or nearly spherical, powder particles being formed upon exiting the plasma discharge where the droplet undergoes rapid cooling and freezes. Quite often, the bulk density of these spherical particles is higher than that of the starting material (Boulos, Fauchais and Pfender, 2013, p. 42). The different plasma spheroidisation techniques reported include radio frequency (RF) induction thermal plasmas (Jiang and Boulos, 2006; Károly and Szépvölgyi, 2005; Yuming, Junjie and Yanwei, 2013), nontransferred direct current (DC) thermal plasmas (Chaturvedi et al., 2014; Kumar and Selvarajan, 2008; Suresh, Selvarajan and Vijay., 2008) and microwave-assisted plasma processing methods (Chen, Gleiman and Phillips, 2001; Vanamu et al., 2004; Weigle et al., 2004).

In this work, a microwave plasma system, similar to that reported in an earlier paper (van Laar et al., 2015b), was used to investigate the potential for spheroidisation of iron powders. Argon served as the carrier gas and the system operated at atmospheric pressure.

\section{Experimental}

\section{Apparatus}

The experimental set-up consisted of a quartz tube placed perpendicular through a metallic waveguide, connected to a microwave generator operating at $2.45 \mathrm{GHz}$. The magnetron was powered by a $1.5 \mathrm{~kW}$ power supply. The quartz tube, with internal diameter

* Applied Chemistry Division, South African Nuclear Energy Corporation (NECSA) SOC Ltd., Pelindaba, North West Province, South Africa.

+ Fluoro-materials Group, Department of Chemical Engineering, Faculty of Engineering, Built Environment and Information Technology, University of Pretoria, Pretoria, South Africa.

(C) The Southern African Institute of Mining and Metallurgy, 2016. ISSN 2225-6253. This paper was first presented at the AMI Ferrous and Base Metals Development Network Conference 2016 19-21 October 2016, Southern Sun Elangeni Maharani, KwaZulu-Natal, South Africa. 


\section{Spheroidisation of iron powder in a microwave plasma reactor}

of $2 \mathrm{~cm}$ and a length of $30 \mathrm{~cm}$, served as the reaction zone and support flanges at the top and bottom of the tube also served as gas inlets. Argon flow rates were controlled using calibrated Aalborg rotameters. This set-up was similar to that described previously (van Laar et al., 2015a) with the addition of a powder feeder positioned above the reactor inlet, as well as a zirconium wool filter at the bottom of the quartz reactor. A schematic representation of the experimental setup is shown in Figure 1. A T-connection and valve assembly subsequent to the reactor set-up allowed for easy shifting between vacuum and atmospheric operating pressures.

Characterization of the particles was performed using equipment at the South African Nuclear Energy Corporation (Necsa), as well as the University of Pretoria (UP). Scanning electron microscopy (SEM) was performed on the particles with a high-resolution $(0.6 \mathrm{~nm})$ JEOL 6000 system using secondary electron (SE) signals.

\section{Method}

At the start of each experimental run, the argon plasma was initiated under vacuum at approximately $15 \mathrm{kPa}$ (Figure 2a), using an Alcatel 2010I dual-stage rotary vane pump. The pressure was then gradually increased by closing the outlet valves, until the pressure reached ambient atmospheric conditions. At this pressure, the plasma became highly filamentary (Cardoso et al., 2009) as shown in Figure 2b. The iron powder was then fed through the plasma zone. During experiments, a dark grey powder deposited on the inner walls of the quartz tubes, as well as on the zirconium wool filter at the bottom of the reactor. After each experimental run, the grey powders were collected from the zirconium wool and the tubes were removed and flushed using acetone. The acetone wash was collected and evaporated in a drying oven operating at $50^{\circ} \mathrm{C}$, after which the powders were collected.

The spheroidisation of the iron powders was investigated at constant conditions, given in Table I. The argon flow rates are reported in standard cubic centimetres per minute ( $\mathrm{sccm})$. Four runs were completed and all results obtained were similar. The results presented in this paper are representative of all product powders. During these runs, the reflected power varied between $100 \mathrm{~W}$ and $200 \mathrm{~W}$. The reflected power is defined as the total power reflected back towards the magnetron, rather than coupling with the gas in the reactor.

\section{Results and discussion}

\section{Optical Microscopy}

The presence of spherical particles within the iron product samples was evident. The initial feed powder showed no

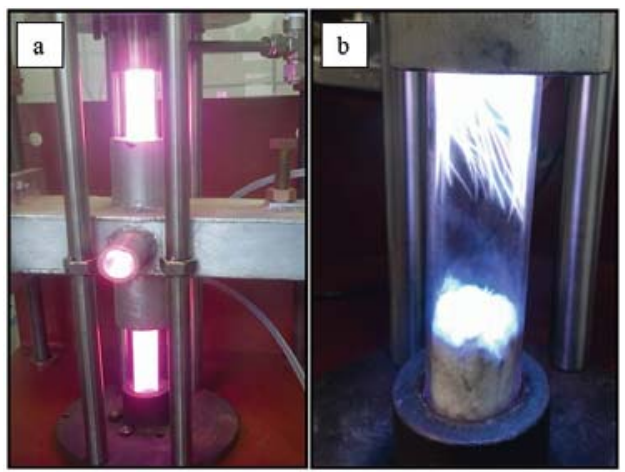

Figure 2-Argon microwave plasma (a) under vacuum and (b) at atmospheric pressure

\begin{tabular}{|c|c|}
\hline \multicolumn{2}{|c|}{$\begin{array}{l}\text { Table I } \\
\text { Experimental parameters of the spheroidisation } \\
\text { experiments }\end{array}$} \\
\hline Parameter & Value \\
\hline $\begin{array}{l}\text { Power } \\
\text { Ar flow } \\
\text { Pressure } \\
\text { Feed rate }\end{array}$ & $\begin{array}{l}1500 \mathrm{~W} \\
150 \mathrm{sccm} \\
1 \mathrm{~atm} . \\
10 \mathrm{~g} / \mathrm{h}\end{array}$ \\
\hline
\end{tabular}

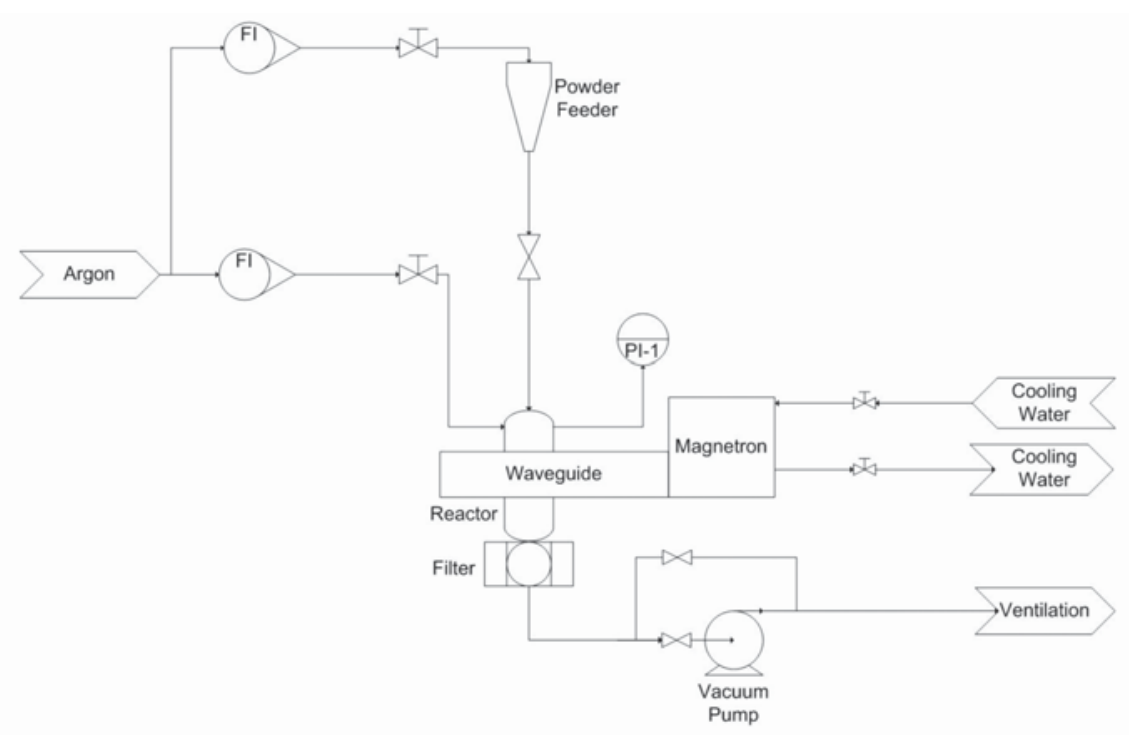

Figure 1-Schematic diagram of the experimental set-up 


\section{Spheroidisation of iron powder in a microwave plasma reactor}

evidence of large spherical particles at the same magnification settings. After the runs, a definite increase in the amount of spherical particles was found, as shown in Figure 3. The degree of conversion to large spherical morphologies appears to be quite low from these images, implying that a large amount of powder passed through the system without undergoing spheroidisation. This was undoubtedly due to the filamentary nature of the plasma, which decreased the total contact area and time of the particles with the high-energy plasma filaments.

\section{Scanning electron microscopy}

SEM images of the iron product are shown in Figure 4. Particle sizes ranged between $20 \mu \mathrm{m}$ and $100 \mu \mathrm{m}$ and the surfaces of the particles were either smooth (Figure $4 \mathrm{a}$ ) or had shallow grooves on the surface (Figure $4 \mathrm{~b}$ ), despite identical operating conditions. The formation of an oxide layer around the particles was also evident from the loosening flakes on the surface, as well as the large white mark, shown in Figure 4b. The different surface morphologies are related to the different flow paths of particles moving through the plasma, resulting in different heating and solidification histories. Li and Ishigaki (2001) hypothesize that the particles with grooved surfaces experience relatively high cooling rates, resulting in the nucleation of polycrystalline particles.

Smaller deposits were also present on the surface of the spheres. These deposits consisted of agglomerated particles ranging between $100 \mathrm{~nm}$ and $200 \mathrm{~nm}$. Their presence was attributed to partial evaporation of the iron feed material within the hot plasma filaments, followed by recondensation (Ishigaki et al., 1995).

The iron feed material was also analysed using SEM micrographs and was shown to consist of much smaller spherical particles with sizes $2-6 \mu \mathrm{m}$, seen in Figure $5 \mathrm{a}$. These particles were agglomerates of nanosized particles (Figure 5b) and were much smaller than the newly-formed spherical particles in the product powders and hence not visible on the optical images shown in Figure 3.

Other interesting structures seen on the particle surfaces include stacked disc-like, rippled structures, shown in Figure 6(a), similar to the spherical particles reported by Che and Norimasa (2006). The cause and mechanism behind these structures are linked to crystal formation. A variety of nanostructures assume icosahedral shapes at scales where the surface forces exceed the bulk forces. However, some forms persist into micro-scales, such as certain face-centred cubic (FCc) metal colloid clusters (de Nijs et al., 2015). The circular discs, magnified in Figure 6(c), are explained through a similar mechanism, by way of body-centred cubic (bcc) cells with (111) hexagonal projections, illustrated in Figure 7 , growing radially outward, resulting in the observed ripples and step edges.

In addition, it is well known that crystal plane orientations of materials can be determined and interpreted as spherical representations using Kikuchi patterns, which are obtained using electron backscatter diffraction (EBSD) techniques (Zhou and Wang, 2007, p. 41). Coincidently, the physical symmetry of the iron particle, highlighted in Figure $6 \mathrm{~b}$, bears a remarkable similarity to that of a ferrite spherical Kikuchi map (SKM) shown in Figure 6d (Day, 2008) with a cubic lattice structure viewed along the (111) orientation.

Also present were nanosized cubic and spherical particles, either from the unmelted feed material or subsequently spheroidised. Another phenomenon is shown in Figure 8, where most of the particle surface was covered

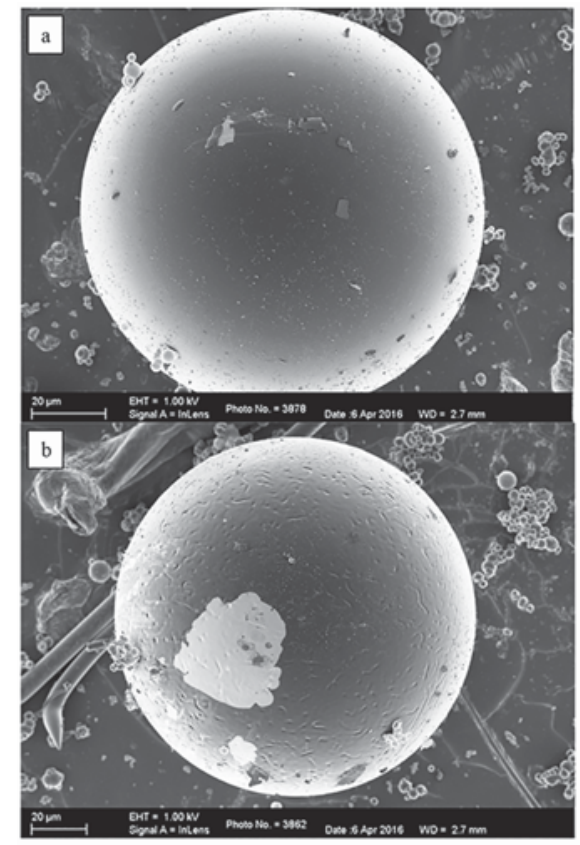

Figure 4-SEM SE images illustrating (a) smooth and (b) rough surfaces

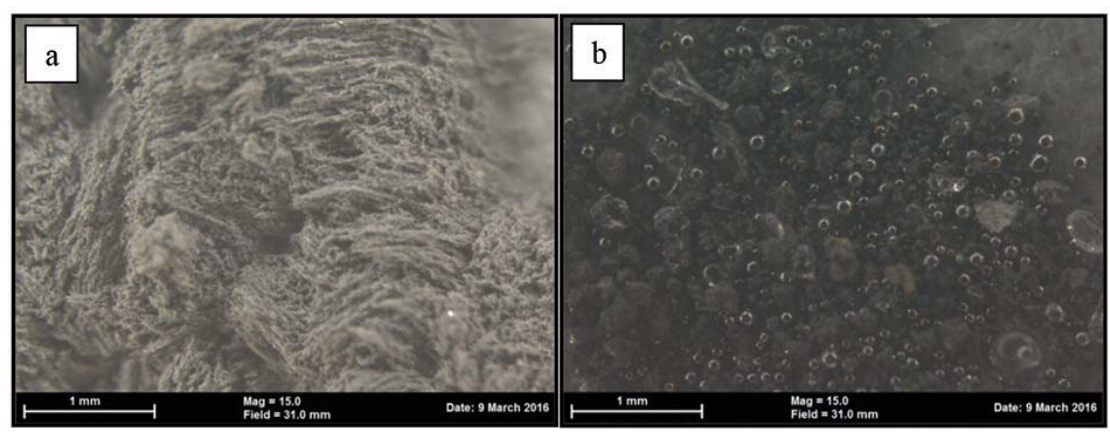

Figure 3-Optical image comparison of the iron powder (a) before and (b) after passing through the microwave plasma 


\section{Spheroidisation of iron powder in a microwave plasma reactor}

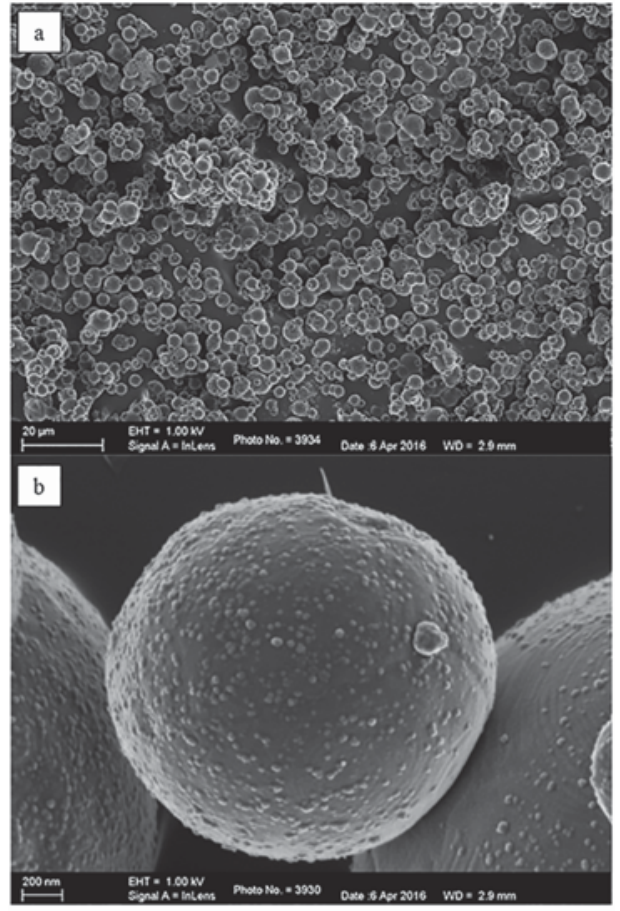

Figure 5-SEM SE images of the iron feed material consisting of (a) smaller spherical agglomerates that were comprised of (b) nanosized particles
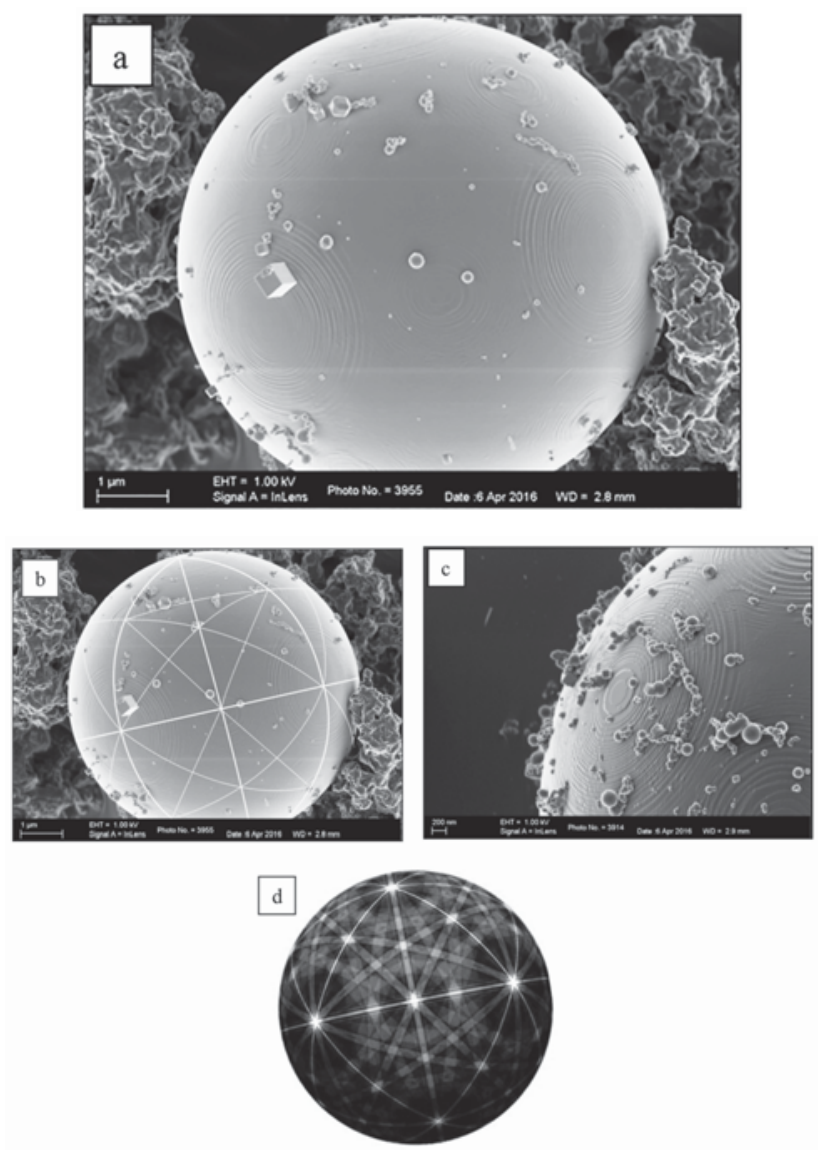

Figure 6-SEM SE morphology of (a) circular discs with (b) highlighted symmetry patterns. The circular discs are magnified (c) and the corresponding Kikuchi pattern (d) is given for ferrite (Day, 2008)

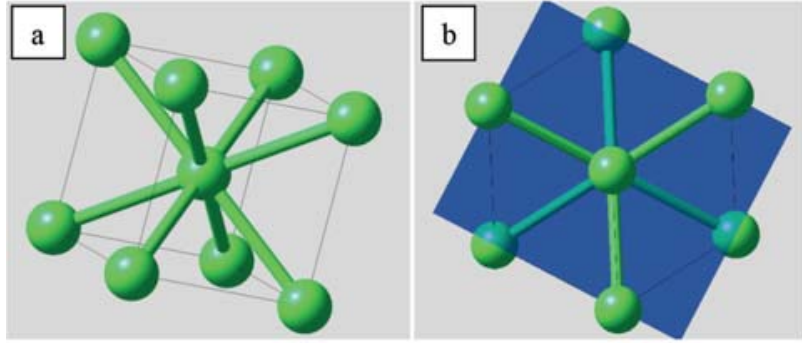

Figure 7-(a) The bcc cell unit with (b) hexagonal projection perpendicular to the (111) plane

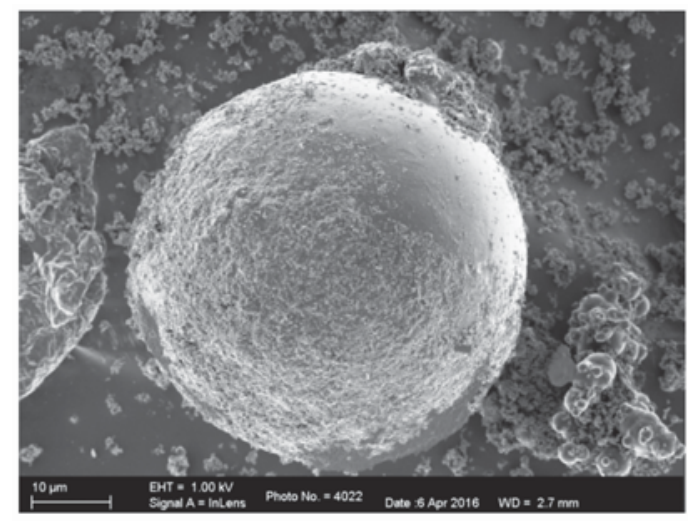

Figure 8-Particles indicative of incomplete melting

with agglomerates consisting of nanosized particles, similar to the feed material. It is possible that these particles did not experience sufficient heating time for uniform melting and solidification to occur.

The internal structures of the particles were also investigated by embedding the particles in an organic resin, followed by grinding and polishing. The polished surface was then viewed using SEM in order to compare internal morphologies. The internal structure of the feed particles is shown in Figure 9d. These particles appeared to contain minor voids and were non-uniform throughout the entire surface area and were easily damaged due to the agglomerated nature of the particles, as indicated in Figure $5 \mathrm{~b}$.

The internal structures of the product particles appeared to be quite diverse, with some particles presenting uniform density throughout the particle (Figure 9a and b), while others displayed larger defects and voids (Figure 9c). The straight lines that appeared on some cross-sections, such as those of Figure 9c, were likely due to the grinder pushing too hard on the surface. An alternative explanation entails a different formation mechanism. Regardless, micro-defects and voids were distinguishable within the structure, especially close to the outer perimeter. It is expected that these internal defects were linked to the outer groove formations in Figure 4b. Li and Ishigaki (2001) speculated that these internal defects are a result of a variation in localized cooling rates, where higher cooling rates impeded the nucleation rate for uniform solidification. 


\section{Spheroidisation of iron powder in a microwave plasma reactor}

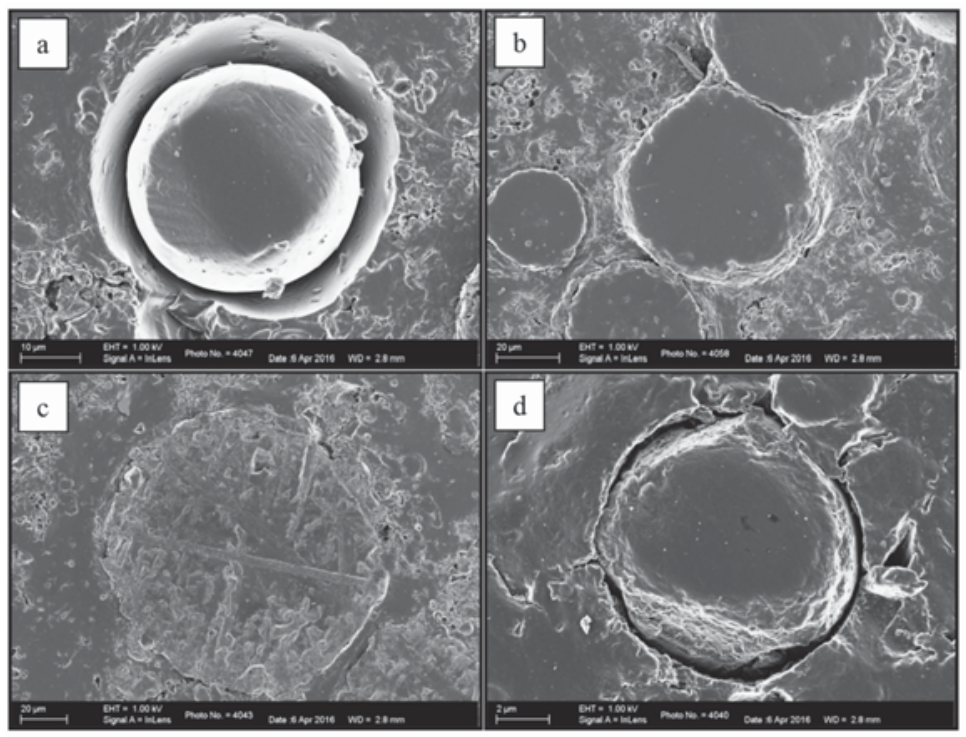

Figure 9-SEM SE images showing the internal cross-section morphologies of spherical iron particles after passing through the microwave plasma

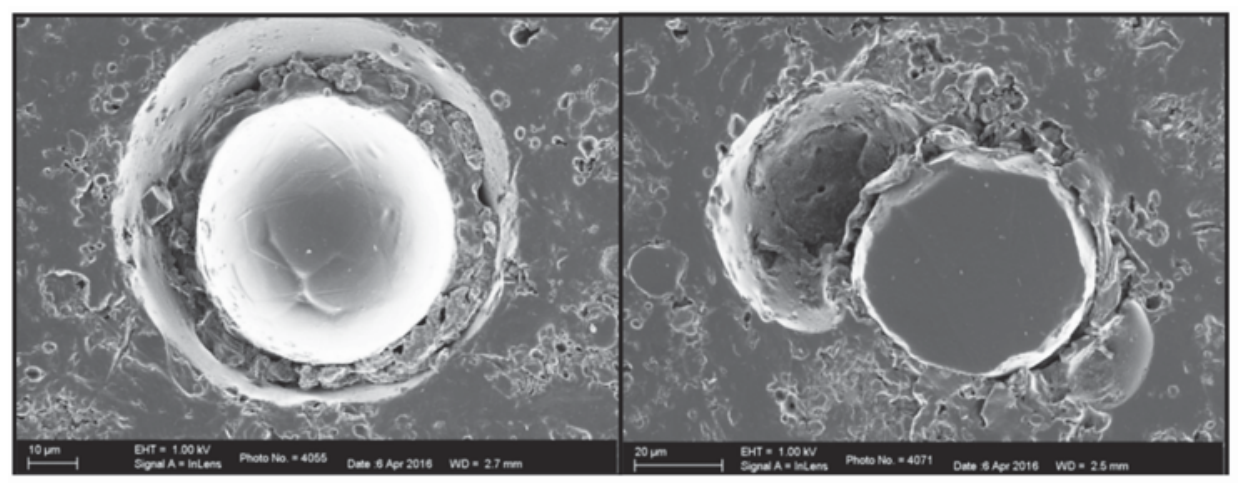

Figure 10-SEM SE micrographs of uniform particles surrounded by a shell consisting of different morphologies

Some particles appeared to possess an outer shell with a different structure from that of the core. Figure 10 presents the cross-sections of particles consisting of a uniformly dense core surrounded by a softer shell. Further investigation revealed the shell to consist of agglomerated structures similar to those of the feed material. The mechanism behind the formation of this shell-and-core structure is unclear; however, one possibility entails the hardening of the organic resin around the particles as they settled to the bottom of the sample during sample sedimentation in the preparation phase.

\section{Heating model}

The experimental results showed that a portion of the iron powders underwent spheroidisation in the argon plasma reactor. Theoretical models (Chen and Pfender, 1982) predict the potential for spheroidisation by first considering the heating time of the material, followed by the melting time. The total time needed is then compared to the residence time of the particles inside the hot plasma environment. These models take into account both the melting point and the thermal conduction of the material, as well as the enthalpy of the plasma gas. Following the model set out by Chen and Pfender (1982) and applied by Li and Ishigaki (2001) for titanium carbide, the heating time, $t_{h}$, is given by

$$
t_{h}=\frac{\rho_{p}}{3} r_{w}^{2} \int_{T_{0}}^{T_{m}} \frac{C_{p} \mathrm{~d} T_{p}}{S_{\infty}-S_{w}}
$$

where $\rho_{p}$ is the density of the solid particles, $r_{w}$ the radius of the particles, $C_{p}$ the heat capacity, $T_{0}$ and $T_{m}$ the starting and melting temperatures respectively and $S_{\infty}$ and $S_{w}$ the thermal conduction potentials of the surrounding gas at plasma temperature and the particle surface, respectively.

The thermal conduction potentials are given by

$$
S=\int_{T_{0}}^{T} k \mathrm{~d} T
$$

where $k$ is the thermal conductivity of the plasma gas. Melting temperature, $t_{m}$, is then determined by

$$
t_{m}=\frac{r_{w}^{2} \rho_{p} L_{m}}{3\left(S_{\infty}-S_{m}\right)}
$$




\section{Spheroidisation of iron powder in a microwave plasma reactor}

where $L_{m}$ is the heat of fusion of the material and $S_{m}$ the thermal conductivity potential of the plasma at the melting point, $T_{m}$, of the material. For an argon plasma at approximately $2000^{\circ} \mathrm{C}$ and using the properties of iron (Chase, 1998), the heating and melting times were calculated and are reported in Table II.

The residence time of the powder was assumed to be the time for which the particles fell through the reactor under the influence of gravity only. It was also assumed that due to the filamentary nature of the plasma, only half of the reactor volume was filled with a plasma discharge. With this assumption, the residence times were approximately $175 \mathrm{~ms}$, orders of magnitude higher than those needed according to the model described above.

\section{Conclusions and recommendations}

A microwave-induced argon plasma was successfully used for the spheroidisation of iron powders. The feed material (2-6 $\mu \mathrm{m})$ underwent melting and droplet formation, followed by rapid cooling and solidification. This resulted in larger spherical particles ranging from $20 \mu \mathrm{m}$ to $100 \mu \mathrm{m}$, often with patterns indicative of the underlying crystallinity mechanisms. SEM confirmed the morphological changes brought about by the process and presented various different particle morphologies. Theoretical models were in relative agreement with regards to the potential for spheroidisation, which was confirmed experimentally.

The use of microwave-assisted plasma shows promise for the spheroidisation of metal powders. However, further experimental work is needed to determine the effect of various operating parameters (such as carrier gas composition and flow rates) on the conversion and spheroidisation ratios. Pending these results, it is recommended that the use of microwave plasma systems be considered for further spheroidisation investigations.

\section{Acknowledgements}

The authors acknowledge the South African National Research Foundation for financial support and the South African Nuclear Energy Corporation for use of their equipment.

\section{References}

BouLos, M. 2004. Plasma power can make better powders. Metal Powder Report, vol. 59. pp. 16-21.

Boulos, M.I., Fauchais, P. and Pfender, E. 2013. Thermal Plasmas: Fundamentals and Applications. Springer, New York.

Cardoso, R.P., Belmonte, T., NoËl, C., Kosior, F. and Henrion, G. 2009. Filamentation in argon microwave plasma at atmospheric pressure. Journal of Applied Physics, vol. 105. p. 093306.

\begin{tabular}{|c|c|c|c|c|}
\hline \multicolumn{5}{|c|}{$\begin{array}{l}\text { Predicted heating and melting times of Fe in the } \\
\text { plasma }\end{array}$} \\
\hline Element & $t_{h}(\mathrm{~ms})$ & $t_{m}(\mathrm{~ms})$ & Total time (ms) & Residence time (ms) \\
\hline $\mathrm{Fe}$ & 1.31 & 0.295 & 1.60 & 175 \\
\hline
\end{tabular}

CHASE, M.W.J. 1998. NIST-JANAF Thermochemical Tables. 4th edn. Journal of Physical Chemistry Ref. Data, Monograph 9. http://webbook.nist.gov

Chaturvedi, V., Ananthapadmanabhan, P.V., Chakravarthy, Y., Bhandari, S. Tiwari, N., Pragatheeswaran, A. and Das, A.K. 2014. Thermal plasma spheroidization of aluminum oxide and characterization of the spheroidized alumina powder. Ceramics International, vol. 40. pp. 8273-8279.

CHE, S. and NorimasA, S. 2006. Preparation and formation mechanism of micrometer-sized spherical single crystal particles of perovskite oxides by flame fusion. Key Engineering Materials, vol. 320. pp. 201-204.

Chen, C.-K., Gleiman, S. and PhilLips, J. 2001. Low-power plasma torch method for the production of crystalline spherical ceramic particles. Journal of Materials Research, vol. 16. pp. 1256-1265.

CHEn, X. and Pfender, E. 1982. Unsteady heating and radiation effects of small particles in a thermal plasma. Plasma Chemistry and Plasma Processing, vol. 2. pp. 293-316.

DAY, A.P. 2008. Spherical EBSD. Journal of Microscopy, vol. 230. pp. 472-86.

De Nijs, B., Dussi, S., Smallenburg, F., MeeldijK, J.D., GroenendijK, D.J., Filion, L., ImHoF, A., vAn BlAAderen, A. and DijKSTRA, M. 2015. Entropy-driven formation of large icosahedral colloidal clusters by spherical confinement. Nature Materials, vol. 14. pp. 56-60.

Fridman, A. 2008. Plasma Chemistry. Cambridge University Press.

ISHIGAKI, T., JUREWICZ, J., TANAKA, J., MoRIYoShI, Y. and Boulos, M.I. 1995. Compositional modification of titanium carbide powders by induction plasma treatment. Journal of Materials Science, vol. 30. pp. 883-890.

JIANG, X.-L. and Boulos, M. 2006. Induction plasma spheroidization of tungsten and molybdenum powders. Transactions of Nonferrous Metals Society of China, vol. 16. pp. 13-17.

KÁROLY, Z. and SzÉPVÖLGYI, J. 2005. Plasma spheroidization of ceramic particles. Chemical Engineering and Processing: Process Intensification, vol. 44. pp. 221-224.

Kumar, S. and Selvarajan, V. 2006. Spheroidization of metal and ceramic powders in thermal plasma jet. Computational Materials Science, vol. 36. pp. 451-456.

Kumar, S. and Selvarajan, V. 2008. Plasma spheroidization of iron powders in a non-transferred DC thermal plasma jet. Materials Characterization, vol. 59. pp. 781-785.

LI, Y.-L. and ISHIGAKI, T. 2001. Spheroidization of titanium carbide powders by induction thermal plasma processing. Journal of the American Ceramic Society, vol. 84. pp. 1929-1936.

Suresh, K., Selvarajan, V. and VijaY, M. 2008. Synthesis of nanophase alumina, and spheroidization of alumina particles, and phase transition studies through DC thermal plasma processing. Vacuum, vol. 82 . pp. 814-820.

VAn LaAr, J.H., Slabber, J.F.M., Meyer, J.P., van der Walt, I.J., Puts, G.J. and CRouSE, P.L. 2015a. Microwave-plasma synthesis of nano-sized silicon carbide at atmospheric pressure. Ceramics International, vol. 41. pp. 4326-4333.

Van LaAr, J.H., van der Walt, I.J., Bissett, H., Puts, G.J. and Crouse, P.L. 2015b. Synthesis and deposition of silicon carbide nanopowders in a microwave-induced plasma operating at low to atmospheric pressures. Journal of the Southern African Institute of Mining and Metallurgy, vol. 115. pp. 949-955.

Vanamu, G., Lester, K., Datye, A.K., Weigle, J.C., Chen, C.-K., Kelly, D. and PHILLIPS, J. 2004. Modifying irregular titania powders in a low power microwave plasma torch. AIChE Journal, vol. 50. pp. 2090-2100.

Weigle, J.C., Luhrs, C.C., Chen, C.K., Perry, W.L., Mang, J.T., Nemer, M.B., LoPEZ, G.P. and PHILLIPS, J. 2004. Generation of aluminum nanoparticles using an atmospheric pressure plasma torch. Journal of Physical Chemistry B, vol. 108. pp. 18601-18607.

Yuming, W., JunjIE, H. and YAnweI, S. 2013. Spheroidization of Nd-Fe-B powders by RF induction plasma processing. Rare Metal Materials and Engineering, vol. 42. pp. 1810-1813.

ZHou, W. and WANG, Z.L. 2007. Scanning Microscopy for Nanotechnology: Techniques and Applications. Springer, New York. 